\title{
Feeding Experiments on Vittina Turrita (Mollusca, Gastropoda, Neritidae) Reveal Tooth Contact Areas and Bent Radular Shape During Foraging
}

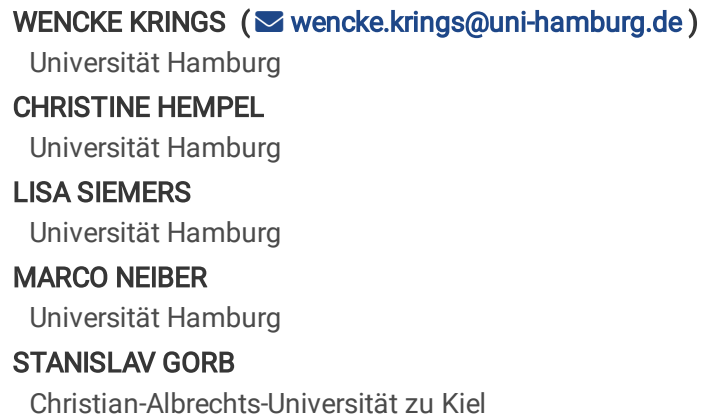

Research Article

Keywords: Interface, radula, function, feeding, biomechanics, wear, abrasion, biotribology

Posted Date: January 14th, 2021

DOI: https://doi.org/10.21203/rs.3.rs-143634/v1

License: (c) (7) This work is licensed under a Creative Commons Attribution 4.0 International License. Read Full License 


\section{Abstract}

The radula is the food gathering and processing structure and one important autapomorphy of the Mollusca. It is composed of a chitinous membrane with small, embedded teeth representing the interface between the organism and its ingesta. In the past, various approaches aimed at connecting the tooth shapes, which are highly distinct within single radulae due to their different functions. However, conclusions from the literature have been mainly drawn from microscopical analyses of mounted radulae, but the real interacting radular parts - even though the precise contact areas are essential for determining a tools functionality - and the 3D architecture of this complex feeding structure have not been previously determined. In the experimental approach presented here individuals of Vittina turrita (Neritidae, Gastropoda) were fed with algae paste attached to different sandpaper types. By comparison with radulae from a control group, sandpaper-induced tooth wear patterns were identified and both the area and volume loss were quantified. In addition to the exact contact area of each tooth, conclusions about the 3D position of teeth and the radular bending during feeding motion could be drawn. Furthermore, hypotheses about the specific functions of individual tooth types could be put forward. This kind of feeding experiments under controlled conditions is new for Mollusca and may provide a good basis for future studies on the radula functional morphology. It can be potentially applied to species with distinct tooth morphologies and ecological niches.

\section{Introduction}

Gastropod diversity is accompanied by feeding on a variety of ingesta sources allowing the establishment of distinct ecological niches. The interface between the animal and the food intaken is the radula consisting of a thin, flexible, and chitinous membrane with teeth arranged in transversal and longitudinal rows [e.g. 1-2] which are constantly re-growing in its posterior part, the building zone, and digested in its anterior part, the degenerative zone [e.g. 2-10]. During foraging, this membrane is either pulled across or spanned between the odontophoral cartilages by buccal mass musculature resulting in the tearing of ingesta and the collection of loosened particles. The sliding contact between teeth and the substrate eventually leads to the tooth wear.

As the quantity, shape, arrangement, material properties, and chemical composition of teeth can be highly distinct within one individual radula and between molluscan taxa, hypotheses about distinct tooth functionalities, additionally to hypotheses about their adaptations to distinct ingesta-types, are at hand. Past approaches on radular functional principles involve the observation and documentation of foraging behavior [11-16] or the analysis of radular feeding tracks $[2,11-12,15,17-24]$. However, as the radular motion is highly complex, the teeth are rather small, and feeding tracks are difficult to interpret, the precise function and the interplay between different radular structures (the membrane, the tooth rows, the odontophoral cartilages, the buccal mass musculature) still await further structural and especially experimental investigation. Additionally, to deeply understand the functionality of a grinding tool - here the radular tooth -, the precise area of contact - here with the ingesta - must be determined. This is essential from the tribological point of view, since the shape of the interacting part determines its capability to transfer forces [e.g. 25-33; for review see 34].

To determine teeth contact areas and to reconstruct the interplay between radular structure, we here present an approach involving feeding experiments with the neritid gastropod Vittina turrita (Gmelin, 1791 [35]) on sandpapers of distinct dimension of particles and therefore with different abrasiveness. This species was chosen, since it possesses radula with highly distinct tooth morphologies. As result from the interaction of the radula with the sandpapers, some tooth regions obtain specific wear patterns and facets identifying the areas of contact and leading to hypotheses about the functionality of each tooth type. The documented ontogeny of wear led to conclusions about the 3D position of teeth on the membrane and the configuration of the radula during foraging.

\section{Methods}

For feeding experiments, 40 individuals of Vittina turrita (Gastropoda: Neritidae) were obtained from online pet shop (garnelio.de; there labeled as Neritina turrita). This species was chosen for our experimentation, because (1) it possesses a heterodont radula with very distinct tooth morphologies and sizes, (2) animals are easy to obtain, shelter, and feed, (3) and videos of radular motion are available [16].

Vittina turrita with a shell height of 15-26 mm (Fig. 2A), inhabits brackish mangroves and riverine environments in the area between Indonesia and Thailand [36]. Since these gastropods need brackish water to breed, $V$. turrita is usually collected in its habitat and exported for international aquarium trade. Species determination was conducted after experiments on the basis of shell and operculum morphology following [36]. Gastropods were killed by short boiling, subsequently preserved in 70\% ethanol, and inventoried in the malacological collection of the Zoologisches Museum Hamburg (ZMH) of the Centrum für Naturkunde (CeNak) (ZMH 154753).

For experiments, adult gastropods were separated into four freshwater aquariums either lined with water-resistant sandpapers (45PCS sandpaper, Shenzhen Take Tools Co., Ltd., Guangdong, China) coated with sharp aluminum-oxide grains of distinct abrasiveness (from fine to rough: $\mathrm{P} 800=$ super fine [with $\mathrm{N}=10$ gastropods], $\mathrm{P} 600$ = extra fine [with $\mathrm{N}=10$ gastropods], $\mathrm{P} 180$ = very fine [with $\mathrm{N}=10$ gastropods]) or without sandpaper (control group; $\mathrm{N}=10$ gastropods). Sandpapers were characterized according to ISO 25178 employing a Keyence VR 3100 (KEYENCE, Neu-Isenburg, Germany) and quantified (Table 1, Fig. 1), to relate the size of sandpaper particles to the size of the radula and single teeth. Gastropods were fed daily for seven to eight weeks with algae paste (Schneckenfeed Paste, NatureHolic GmbH, Mannheim, Germany) which was either attached to the glass surface (control group) or to the sandpaper. After experiments, individuals were killed by short boiling, dissected, radulae first extracted, then digested with proteinase $\mathrm{K}$ according to the protocol of [37], and cleaned by a short, ultrasonic bath. Then they were arranged on scanning electron microscope (SEM) sample holders, air dried, coated with gold-palladium, and documented with the Tabletop microscope TM 4000 Plus (Hitachi, Tokyo, Japan) or the Zeiss LEO 1525 (One Zeiss Drive, Thornwood, USA) (Figs. 2, 4-7, 10). 
Table 1

Parameters of the sandpapers used in feeding experiments (characterized employing the Keyence VR 3100).

\begin{tabular}{|llll|}
\hline \multicolumn{4}{|c|}{ Sandpaper types } \\
\hline Grit number & P 180 - & P $600-$ & P $800-$ \\
& very fine & extra fine & super fine \\
\hline Roughness, $\mu \mathrm{m}, \mathrm{Ra}$ & 21.1 & 5.2 & 3.8 \\
\hline Mean width, $\mu \mathrm{m}, \mathrm{RSm}$ & 195.7 & 28.1 & 22.3 \\
\hline Mean height of profile elements, $\mu \mathrm{m}, \mathrm{Rc}$ & 80.6 & 19.1 & 17.5 \\
\hline
\end{tabular}

Wear was identified by comparison of teeth of experimental animals that fed on the polishing paper substrates with teeth of the control group. To document the wear patterns and the loss of the tooth cusp area, the tooth types showing signs of wear (inner 15 marginal teeth, lateral tooth II, lateral tooth I) of every second tooth row were first outlined with Adobe Illustrator CS 6 (Adobe Inc., San José, USA) (Fig. 7). Afterwards the outlines were translated into areas. Areas were transferred to Adobe Photoshop CS 6 (Adobe Inc., San José, USA), where the number of pixels was read out for each area. By comparing the unworn tooth areas with areas of worn teeth, the percentage of the area loss was determined and could thus be quantitatively analyzed (Table 2 ).

Table 2

Mean tooth area of the distinct tooth parts (cusp, stylus, basis) present in every second row (tooth row 1 = outermost row [oldest and most frequently used

\begin{tabular}{|c|c|c|c|c|c|c|c|c|c|c|c|c|c|c|}
\hline \multirow{3}{*}{$\begin{array}{l}\text { Tooth } \\
\text { structure } \\
\text { Sandpaper }\end{array}$} & \multicolumn{6}{|c|}{ Inner 15 marginal teeth } & \multicolumn{8}{|c|}{ Lateral II } \\
\hline & \multicolumn{3}{|l|}{ Cusp } & \multicolumn{3}{|l|}{ Stylus } & \multicolumn{3}{|l|}{ Cusp } & \multicolumn{3}{|l|}{ Basis } & \multicolumn{2}{|l|}{ Stylus } \\
\hline & Very & Extra & Super & Very & Extra & Super & Very & Extra & Super & Very & Extra & Super & Very & Extra \\
\hline ype & fine & fine & fine & fine & fine & fine & fine & fine & fine & fine & fine & fine & fine & fine \\
\hline & 0.00 & 0.00 & 0.00 & 67.81 & 69.42 & 66.91 & 0.00 & 0.00 & 0.00 & 80.78 & 84.57 & 70.40 & 61.29 & 85.29 \\
\hline & 0.00 & 0.00 & 0.00 & 73.56 & 78.78 & 69.60 & 0.00 & 0.00 & 0.00 & 100.00 & 100.00 & 85.67 & 63.24 & 92.16 \\
\hline \\
\hline & 16.73 & 16.85 & 8.63 & 100.00 & 100.00 & 87.41 & 16.78 & 24.83 & 0.00 & 100.00 & 100.00 & 100.00 & 73.04 & 98.04 \\
\hline \multicolumn{15}{|c|}{6} \\
\hline & 37.06 & 37.09 & 16.75 & 100.00 & 100.00 & 100.00 & 46.64 & 39.26 & 19.80 & 100.00 & 100.00 & 100.00 & 92.65 & 100.00 \\
\hline \multicolumn{15}{|c|}{8} \\
\hline & 86.80 & 86.83 & 68.02 & 100.00 & 100.00 & 100.00 & 81.21 & 90.27 & 43.96 & 100.00 & 100.00 & 100.00 & 100.00 & 100.00 \\
\hline & & & & & & & & & & & & & & \\
\hline 1 & 100.00 & 100.00 & 100.00 & 100.00 & 100.00 & 100.00 & 100.00 & 100.00 & 100.00 & 100.00 & 100.00 & 100.00 & 100.00 & 100.00 \\
\hline
\end{tabular}

To obtain tooth 3D model suitable for calculating tooth volume loss, for the definition of the tooth sections (Fig. 3), and for visualization the tooth's position on the radula, and the proposed shape during feeding (Figs. 8-9), the teeth were formed manually. Since the teeth are rather small and of low x-ray contrast, they could not be visualized with $\mu-C T$ technique, as it has been applied in previous studies of radular tooth morphology [10, 38]. To create a 3D model of distinct teeth following the protocol of [39], radulae of two additional specimens sheltered without sandpaper were extracted, digested, cleaned, and mounted on SEM sample holders. To obtain images from all sides of an individual tooth, the unworn but mature part of the radula was manually destroyed, teeth were extracted, twisted, mounted, and finally visualized using the SEM Zeiss LEO 1525. Using the 3D software Maya 2019 (Autodesk, Inc., San Rafael, USA), the teeth were then virtually formed by hand always comparing the computer model with the SEM images taken from different sides. To simulate the tooth wear, the final 3D model of each individual tooth was remodeled by employing the tool 'booleans: difference' in Maya 2019: manually modeled cubes or spheres were subtracted from the tooth's 3D model until the model (Fig. 9) looked similar to the worn teeth taken in the SEM. The volume of the model before and after this procedure was calculated in Maya 2019 employing the tool 'measurements'. Thus, the tooth volume loss in \% could be determined (Table 3 ). 
Table 3

Tooth volume of the distinct teeth (lateral I, lateral II, inner 15 marginal teeth) present in every second row (tooth row 1 = outermost row [oldest and most frequently used one]; tooth row $11=$ first [youngest] row with slight signs of wear) after foraging on sandpaper (very fine, extra fine, super fine), in \%, estimated by manipulating the 3D model until it looks similar to the worn teeth.

\begin{tabular}{|c|c|c|c|c|c|c|c|c|c|}
\hline \multirow{2}{*}{$\begin{array}{l}\text { Tooth } \\
\text { type } \\
\text { Sandpaper } \\
\text { type }\end{array}$} & \multicolumn{3}{|c|}{ Inner 15 marginal teeth } & \multicolumn{3}{|c|}{ Lateral II } & \multicolumn{3}{|l|}{ Lateral I } \\
\hline & $\begin{array}{l}\text { Very } \\
\text { fine }\end{array}$ & $\begin{array}{l}\text { Extra } \\
\text { fine }\end{array}$ & $\begin{array}{l}\text { Super } \\
\text { fine }\end{array}$ & $\begin{array}{l}\text { Very } \\
\text { fine }\end{array}$ & $\begin{array}{l}\text { Extra } \\
\text { fine }\end{array}$ & $\begin{array}{l}\text { Super } \\
\text { fine }\end{array}$ & $\begin{array}{l}\text { Very } \\
\text { fine }\end{array}$ & $\begin{array}{l}\text { Extra } \\
\text { fine }\end{array}$ & $\begin{array}{l}\text { Super } \\
\text { fine }\end{array}$ \\
\hline 1 & 73.11 & 73.95 & 72.69 & 37.53 & 39.81 & 36.59 & 80.58 & 83.06 & 76.86 \\
\hline 3 & 78.15 & 78.15 & 73.11 & 37.73 & 45.11 & 36.59 & 87.60 & 91.32 & 78.10 \\
\hline 5 & 80.25 & 80.25 & 78.15 & 67.78 & 70.69 & 47.40 & 93.80 & 95.45 & 78.93 \\
\hline 7 & 92.86 & 92.86 & 80.25 & 83.06 & 81.19 & 67.67 & 100.00 & 100.00 & 83.47 \\
\hline 9 & 97.90 & 97.90 & 96.22 & 100.00 & 100.00 & 82.95 & 100.00 & 100.00 & 87.19 \\
\hline 11 & 100.00 & 100.00 & 100.00 & 100.00 & 100.00 & 100.00 & 100.00 & 100.00 & 100.00 \\
\hline
\end{tabular}

Feeding tracks of radulae were recorded by melting paraffin and applying it onto a petri-dish evenly. This was placed into the aquarium with algae paste spread over it. After one day, the petri-dish was dried, controlled by microscope, and found feeding tracks were visualized and analyzed with a Keyence VHX7000 (KEYENCE, Neu-Isenburg, Germany) (Fig. 11).

\section{Results}

\section{Radular structure and feeding tracks}

The radula of $V$. turrita possess $\sim 150$ tooth rows along its longitudinal axis (for anatomic directions, see Fig. 2B). Each transversal row consists of one central tooth (or rachidian tooth, R), flanked to each side by one lateral tooth (lateral I), one large and dominant lateral tooth (lateral II), and approximately 40 thin marginal teeth (Fig. 2). Thus, the following tooth row formula can be compiled: $40+1+1+R+1+1+40$.

The central tooth is rectangular, $\sim 52-70 \mu \mathrm{m}$ wide (6-7\% of one transversal row), $51-74 \mu \mathrm{m}$ long, and $40-43 \mu \mathrm{m}$ high (all parameters measured are defined in Fig. 3). Lateral I exhibits a broad, shoulder blade-shaped basis and a 7-10 $\mu \mathrm{m}$ long thickening or edge. It is $135-173 \mu \mathrm{m}$ wide (15-18\% of one transversal row), at maximum 58-75 $\mu \mathrm{m}$ long, its medial part 28-33 $\mu \mathrm{m}$ high, and its lateral part 7-9 $\mu \mathrm{m}$ high. Lateral II is of roundish shape with a broad basis and stylus merging with a thick cusp, which possesses one larger and multiple smaller denticles; it is only $110-152 \mu \mathrm{m}$ wide (14-15\% of one transversal row), but dominant and prominent through its height (maximal 90-110 $\mu \mathrm{m}$ high). The central part of the cusp is thickened (33-39 $\mu \mathrm{m})$, the part interacting with the ingesta is thinner ( $9-17 \mu \mathrm{m}$ thick). Between lateral I and lateral II, two smaller, interlocking structures are documented (e.g. Fig. $5 \mathrm{E}$ ) which could be reduced teeth [see 40] or hardenings of the membrane. Both together are $42-50 \mu \mathrm{m}$ wide (5-6\% of one transversal row) and 52-77 $\mu \mathrm{m}$ high. The marginal teeth consist of a stylus (8-12 $\mu \mathrm{m}$ wide) and a cusp. The inner 15 marginal teeth differ in their morphology from the outer 25 ones. The inner marginal teeth possess a stylus ( $80-110 \mu \mathrm{m}$ high, $20-30 \mu \mathrm{m}$ thick) and a cusp (27-40 $\mu \mathrm{m}$ long, $3-4 \mu \mathrm{m}$ thick) with few small denticles. The lateral marginal teeth possess a higher and thinner stylus (100-150 $\mu \mathrm{m}$ high, 3-6 $\mu \mathrm{m}$ thick) and a shorter and thinner cusp (18-27 $\mu \mathrm{m}$ long, $2-3 \mu \mathrm{m}$ thick) with more and thinner denticles. When all marginal teeth are manually fanned out and unfolded, they make up 43-45\% of one transversal row. However, under natural conditions, these teeth rather cluster together and seem agglutinated. Only the cusps of the lateral tooth II leave feeding tracks on the paraffin surface (Fig. 11).

\section{Sandpaper-induced wear patterns}

Wear is only found in the outermost 11 tooth rows ( $7 \%$ of the whole radula, Figs. 4-6; for wear schemes and tooth area loss see Fig. 7$)$. Wear was only documented for lateral I, lateral II, and the 15 inner marginal teeth. The central tooth, as well as the remaining marginal teeth, did not show signs of wear (Figs. $2,4-7)$.

Highest degree of wear was documented in the radulae from specimens foraging on the finest (super fine; Fig. 4), followed by the roughest (very fine; Fig. 6 ), and finally the medium sandpaper (extra fine; Fig. 5) (see Tab. 2 and Fig. 7 for the tooth area loss and Tab. 3 for tooth volume loss per tooth type and row).

The super fine sandpaper (with the mean width of one abrasive particle $=\sim 2 \%$ of one transversal tooth row width) causes at maximum a tooth area loss of $\sim 57 \%$ for one transversal row. In this process, the lateral I loses $\sim 50 \%$ area and $\sim 23 \%$ volume, the lateral II $\sim 57 \%$ area and $\sim 63 \%$ volume, and the 15 inner marginal teeth $\sim 67 \%$ area and $\sim 27 \%$ volume. The extra fine sandpaper (with the mean width of one abrasive particle $=\sim 4 \%$ of one transversal tooth row width) leads to a maximal tooth area loss of $\sim 41 \%$ for one transversal row; the lateral I loses $\sim 15 \%$ area and $\sim 17 \%$ volume, the lateral II $\sim 43 \%$ area and $\sim 60 \%$ volume, and the inner 15 marginal teeth $\sim 66 \%$ area and $\sim 26 \%$ volume. The very fine sandpaper (with the mean width of one abrasive particle $=\sim 19 \%$ of one transversal tooth row width) causes a maximal tooth area loss of $\sim 48 \%$ for one transversal row; here the lateral I loses $\sim 24 \%$ area and $\sim 19 \%$ volume, the lateral II $\sim 53 \%$ area and $\sim 60 \%$ volume, and the inner 15 marginal teeth $\sim 66 \%$ area and $\sim 27 \%$ volume. 


\section{Wear on the lateral tooth I}

The highest tooth area and tooth volume loss were documented for interaction with the super fine (one sandpaper particle $=\sim 13-17 \%$ of the tooth), followed by the very fine (one sandpaper particle $=\sim 113-117 \%$ of the tooth), and finally the extra fine sandpaper (one sandpaper particle $=\sim 16-21 \%$ of the tooth)

High wear is documented for the lateral edge of the cusp, becoming thinner and thinner through the ongoing interaction with the abrasive surface, and the lateral edges of its basis. By interacting with the super fine sandpaper, the cusp lost an area of maximal $\sim 53 \%$ and the basis maximal $\sim 46 \%$ (for both tooth parts signs of wear start at the row 9). In the process of ongoing interaction between the tooth and very fine sandpaper, the basis maximally lost $\sim 24 \%$ area (first signs of wear at the row 9 ) and the cusp maximally lost 24\% (first signs of wear at the row 5). After the interaction with the extra fine sandpaper, the lateral I was worn down least. Its cusp maximally lost $\sim 16 \%$ (first signs of wear at the row 9 ) and its basis maximally lost $\sim 13 \%$ of its area (first signs of wear at the row 7).

\section{Wear on the lateral tooth II}

The lateral II shows overall the highest degree of wear and loss of both area and volume in each radula, starting at the medial part of the cusp. After the cusp is worn down first, the stylus and then the basis are affected, since they became exposed to the substrate.

The highest tooth area and tooth volume loss was again documented for interaction with the super fine (one sandpaper particle $=\sim 15-20 \%$ of this tooth), followed by the very fine (one sandpaper particle $=\sim 128-177 \%$ of this tooth), and finally the extra fine sandpaper (one sandpaper particle $=\sim 18-26 \%$ of this tooth). After the interaction with the super fine sandpaper, the tooth area and volume loss started at the medial part of its cusp: the cusp is completely worn down in the row 5 already, thus, stylus and basis became exposed. With a decreasing tooth cusp area, the stylus interacts more frequently with the abrasive substrate (first signs of wear were observed at the row 7 ) until a u-like structure is retained at the maximal degree of wear (maximal 37\% of the stylus area loss). The wear on the basis started in the row 3: maximal $30 \%$ of the basis area was lost. When foraging on the very fine sandpaper, the cusp is worn down completely in the row 3 : the stylus had a maximal area loss of $\sim 30 \%$. The basis showed signs of wear only in the row 1 . The lateral II showed the smallest degree of wear after interaction with the extra fine sandpaper. Cusps are affected first at their lateral parts and completely lost from the row 3 on: stylus (wear started in the row 1; maximal area loss of $\sim 15 \%$ ) and basis (wear started in the row 1; maximal area loss of $\sim 15 \%$ ) show very small signs of wear.

\section{Wear on the 15 inner marginal teeth}

Only the 15 inner marginal teeth showed signs of wear appearing first at their cusps. Their styli always showed vertically running wear pattern: they were worn down after the cusps are lost. The medial teeth were affected most and the outer ones least.

The highest tooth area and tooth volume loss was again documented for interaction with the super fine (one sandpaper particle $=\sim 185-279 \%$ of the tooth stylus), followed by the very fine (one sandpaper particle $=\sim 1630-2246 \%$ of the tooth stylus), and finally extra fine sandpaper (one sandpaper particle $=$ $\sim 234-351 \%$ of the tooth stylus). When foraging on the super fine sandpaper, the tooth cusps have already lost $\sim 32 \%$ of their area in the row 9 . Additionally, styli and bases, especially of the medial teeth, showed heavy signs of wear. At the row 5 , the cusps possessed only half of their area than the tooth cusps of the same row from the individuals fed on the very and extra fine sandpapers. After the interaction with the very fine sandpaper, the first signs of wear on the cusps were found in the row 9 . First, the denticles were eroded, then the cusp was lost (the medial marginal teeth have lost their cusp in the row 3 ), and the teeth have lost their height. When the cusps were eroded, the bases were exposed and affected by wear (the medial marginal teeth showed wear at their basis in the row 5; maximal tooth area loss $\sim 32 \%$ ). The extra fine sandpaper induced wear patterns at the basis and cusp of the marginal teeth (the medial marginal teeth showed wear in their basis in the row 5; maximal tooth area loss 31\%) similar to the super fine sandpaper. The only differences in induced wear patterns were observed for the bases, less worn down by the extra fine sandpaper.

\section{The appearance and development of wear}

Unnatural wear can appear in three distinct forms: scratches, fractures, and spalling (Fig. 10). The feeding on a glass surface does not cause such impacts on the radula of $V$. turrita. The first interaction with abrasive substrate asperities usually leads to well-defined scratches on the tooth surface. With ongoing contact with the sandpaper, fractures in tooth material can be detected, subsequently followed by spalling.

\section{Discussion}

The position of individual teeth on the radular membrane, while foraging, is essential for understanding their functionality as each component may contribute differently to the distribution of stress or to the prevention of structural failure depending on its angle during the contact with the substrate and on its interactions with other teeth. In many previous works, it was assumed that the radula is pulled by muscles parallel to and flat across the odontophoral cartilages and that the teeth are oriented thus more or less parallel to each other presumably functioning like a rasp, a pulley, or a conveyer belt [e.g. 11,19,4145]. This configuration would be more or less similar to the mounted radulae on the SEM stubs (Figs. 2, 4-7). However, by manually protruding the radula from dead gastropods, it was documented that the radula is not flat outside of the mouth, but has rather a curved shape with teeth oriented in semi-circles and distinct angels to one another [46]. Unfortunately, this hypothesis again does not reflect the exact configuration of the teeth during feeding, since the radula in [46] was put out quite far from the mouth opening. By observing and documenting feeding gastropods through transparent glass, complex motion patterns, highly distinct between taxa, and a bent shape of radula can be observed [for Vittina see 16; for other gastropods see 11-15]. However, these approaches do not precisely allow, due to the smallness of the radular teeth, the identification of the position of individual teeth relatively to each other, as well as the precise contact areas of teeth with the surface. Analyses of radular feeding tracks on flat surfaces provide important indications that teeth are capable of moving, 
twisting, and rotating during foraging $[2,11-12,17,23,46]$ but again, precise tooth-ingesta-contact areas are hard to determine. The here presented experimental approach, involving sandpapers with distinct dimensions of asperities and analyzing sandpaper-induced wear facets, allowed us a good determination of radular parts interacting with the substrate. Furthermore, some inferences about the relative position of teeth on the membrane during foraging can be deduced from the ontogeny of wear.

First wear traces appear on the medial part and large denticle of the lateral II cusp. Once the height of the denticle is reduced, both lateral edges of the lateral I interact with the substrate and are will be worn later. The 15 inner marginal teeth also show signs of wear on their styli and cusps after the lateral II cusp is affected and worn down. Here a gradually increasing wear from medial to lateral side within the array of marginal teeth is observed. The central tooth, the medial part of the lateral I, and the outer marginal teeth - even though they are the longest radular teeth - do no show signs of wear, which in turn means that they all do not directly interact with the substrate while foraging. These observations lead to the hypothesis that the radular membrane must be bent during feeding, probably in the shape of an inverse w along the transversal axis (Figs. 8A, 9A). Additionally, wear on the lateral I appears first on the lateral, posterior edge of the basis and later wear appears on the large, anterior 'cutting' edge, even though this edge is higher than the lateral edge of the basis. Thus, the radula must be additionally bent along the longitudinal axis during foraging (Figs. $8 \mathrm{~B}-\mathrm{E}$ ).

Such bending behavior had been previously described for 'Archaeogastropoda', which bent and unfold their radula at their mouth opening to build a broad area for grazing, followed by a folding in the opposite direction, to obtain a smaller structure that can be stored in the head [47]. Also Neritidae can bend their radulae in such a way that the lateral teeth become closer to the substrate than the medial ones $[16,36]$. Here, not the center of the radula, but rather its lateral areas will be mechanically stressed [see also 40].

The radula is situated between two large odontophoral cartilages (Figs. 8A, 9A) [see 48-50] which are controlled by the buccal mass musculature. They could establish a lateral force, possibly supported by the mechanical behavior of the radular membrane, leading to a bent shape of the membrane in $V$. turrita. The central tooth together with the lateral I probably span the radula along the longitudinal axis and the two membrane thickenings or reduced teeth [see 40] act like joints stabilizing the entire structure. Thus, all radular teeth are not oriented parallel either to each other or to the odontophoral cartilages during foraging, which had also been observed for docoglossan radulae of Fissurellidae [10].

Sandpaper has a high impact on the tooth wear. The highest abrasion and distinct scratches are induced by feeding on the super fine sandpaper (Figs. 4, 7). Radulae from specimens sheltered on the very fine and extra fine sandpapers show a smaller degree of abrasion (Fig. 7, Tabs. 2-3), even though abrasive particles have a larger diameter (Fig. 1, Tab. 1). In the case of the very fine sandpaper, particles are even larger than teeth and we would have expected higher impacts from foraging on the larger particles than on the smaller ones. Additionally, scratches on teeth from specimens sheltered on the super fine sandpaper are fine and deep, presumably induced from single, sharp-edged abrasive particles, indicating that teeth do not spread or swerve. The worn teeth from gastropods, sheltered on both rougher sandpapers, rather show fractures and spalling, which also indicates that teeth seem to be cushioned to a certain extent. Either a flexible tooth embedment in the radular membrane allows a spreading of teeth to the sides [see also 39,51-52] and/or a softer cushioning beneath the membrane and embedded teeth in combination with the mechanical behavior of the odontophoral cartilages allows a swerving in dorsal direction, when teeth hit larger asperities [4,6,53-56]. Similar mechanisms have been observed for the anchorage of mammalian teeth [e.g. 57-58].

Natural wear has been documented in various molluscan species [6,8,10,24,44,59-65], but wear-causing agents have not been reported in these publications. The comparison of the results from previous studies with the ones obtained here depicts that the natural wear in Polyplacophora and Patellogastropoda [24] is heavier than the natural wear observed in the radulae from our control group of $V$. turrita. This could be explained by the natural habitat and the ingesta taken in by these taxa, feeding on thick and dense algae covers on solid substrate in the surf zone [e.g. 66]. However, $V$. turrita also inhabiting solid substrate seems to prefer rather porous ingesta [36]. In the first case, the gastropods probably have to exert higher forces to loosen the ingesta that may presumably result in a heavy wear, whereas in the second case gastropods probably have to exert smaller forces resulting in smaller wear. Additionally, docoglossan teeth are harder and stiffer resulting from iron incorporations [e.g. 67-69], whereas neritid teeth are rather soft and more flexible, as they are rather chitinous [70]. Softer teeth probably allow more elastic deformation without damage, when hitting a large obstacle, leading to less wear or structural failure. Sandpaperinduced wear patterns in $V$. turrita are more pronounced than any natural wear documented [for references see above] indicating the limitations of this feeding structure.

The functionality of a grinding tool is - among other parameters - highly determined by its contact areas, which are again determined by the tool's morphology [see review see 34]. Contact areas between the radula of $V$. turrita and ingesta surface are, as stated above, the lateral edges of the lateral $I$, the medial edge of the lateral II, and the cusps and styli of the 15 inner marginal teeth. If a tool/tooth is rather pointy, its contact area is smaller, which in turn means that more pressure can be exerted on the target surface during 'puncturing' [see e.g. 71 for radular teeth; 34 for review on 'puncturing']. Thus, often a small contact area indicates that this part of a structure is rather used for piercing, as the small and pointy denticles on the cusp of the lateral II in $V$. turrita. When the denticles are worn down, the gastropod forages with the remaining cusp of the lateral II, which seems to be the main tool for ingesta loosening [see also 72], which is also indicated by the feeding tracks (Fig. 11). The lateral I does not possess any denticles, but rather two large edges on the lateral side, which interact with the substrate, possibly cutting off ingesta. The 15 inner marginal teeth have contact areas to the substrate with their cusps and styli as it is proven by the wear on both parts. However, marginal teeth are probably not used for puncturing, since they are flexible, but rather for brushing [see also 72] across the substrate and collecting particles by their denticles [for the relationship between hardness and capability of scratching see 15,39,52,71,73]. The hypothesis that neritinomorph marginal teeth are rather used for collecting particles due to their softness and flexibility, whereas both lateral teeth are rather used for loosening ingesta from surfaces had been put forward previously $[44,72,74]$ and is well supported by the result of the present study. However, as the inner marginal teeth show also signs of wear, they are probably, at least temporarily, involved in more intense tooth-ingesta interaction also potentially loosening ingesta. This is well supported by their morphology: the inner marginal teeth possess a thicker and shorter stylus, whereas the outer marginal teeth are rather thin and slender. Thus, the inner marginal teeth are potentially rather capable of exerting higher forces than the outer marginal teeth [for the relationship between radular tooth morphology and function see also 39,52,71,73]. Chemical analyses of the radula of the neritid Nerita atramentosa, 
documenting that the medial marginal teeth are composed of more minerals than the outer ones [70], additionally support this hypothesis. However, whether this is also the case for $V$. turrita awaits further investigations. Stylus and basis of each tooth probably distribute the mechanical stress from their interacting parts to the membrane during foraging and, additionally, stabilize each other laterally, leading to the distribution of stress from medial to lateral side of the radula [see also $44,71,74]$.

Previous hypotheses for neritid radulae stating that the central tooth and the medial edges of the lateral I are used for scratching across ingesta surface and loosening particles $[44,72,74]$ could not be supported by our analyses. Our results clearly show that both structures do not interact with the substrate. Since the central tooth and lateral tooth I rather interact with joint-like edges [for tooth-tooth contact in neritids see also 44,74], both teeth together probably span the radula to its bent shape. The fact that not all radular teeth are involved in the loosening of ingesta (here central teeth) had also been documented for Fissurellidae [10].

Wear patterns on all tooth edges are rather curved and roundish. After the tooth cusps break off, as in the lateral tooth II, the gastropods seem to forage with the remaining stylus, until this structure is also worn down [see also 44]. We did not find any signs of a self-sharpening effect as previously described for chitons, limpets, and echinoderms [10,24,63,75-76]. However, obviously damaged teeth can, to a certain extent, still maintain their function.

\section{Declarations}

\section{Acknowledgements}

We would like to thank Renate Walter from the Zoological Institute of the Universität Hamburg, Germany for her support with the SEM and Frank Friedrich for the evaluation of the bachelor thesis providing the basis for this manuscript. We are grateful for the helpful comments of anonymous reviewers.

\section{Authors' contributions}

W.K. and S.G. initiated the project, discussed data, figures, C.H. analyzed data and provided with her thesis the first draft of the manuscript together with W.K., L.S. provided the 3D models, M.N. performed species identification. All authors contributed to and approved the final manuscript for publication.

\section{Competing Interests Statement}

The authors declare no competing interest.

\section{References}

1. Guralnick, R. \& Smith, K. Historical and biomechanical analysis of integration and dissociation in molluscan feeding, with special emphasis on the true limpets (Patellogastropoda: Gastropoda). Journal of Morphology. 241, 175-195 (1999).

2. Mackenstedt, U. \& Märkel, K. (2001). Radular structure and function. In: G. M. Barker (Ed.), The biology of terrestrial Molluscs (pp. 213-236). New York, USA:CABI Publishing.

3. Runham, N. W. Rate of replacement of the molluscan radula. Nature. 194, 992-993 (1962).

4. Runham, N. W. A study of the replacement mechanism of the pulmonate radula. The Quarterly Journal of Microscopical Science. 104, 271-277 (1963).

5. Isarankura, K. \& Runham, N. W. Studies on the replacement of the gastropod radula. Malacologia. 7, 71-91 (1968).

6. Mackenstedt, U. \& Märkel, K. Experimental and comparative morphology of radula renewal in pulmonates (Mollusca, Gastropoda). Zoomorphology. 107, 209-239 (1987).

7. Lowenstam, H. A. \& Weiner, S. On Biomineralization (Oxford University Press, New York, USA, 1989).

8. Padilla, D. K., Dittman, D. E., Franz, J. \& Sladek, R. Radular production rates in two species of Lacuna Turton (Gastropoda: Littorinidae). Journal of Molluscan Studies. 62, 275-280 (1996).

9. Shaw, J. A., Macey, D. J. \& Brooker, L. R. Radula synthesis by three species of iron mineralizing molluscs: production rate and elemental demand. Journal of the Marine Biological Association of the United Kingdom. 88 (3), 597-601 (2008).

10. Ukmar-Godec, T., Kapun, G., Zaslansky, P. \& Faivre, D. The giant keyhole limpet radular teeth: A naturally-grown harvest machine. Journal of Structural Biology. 192, 392-402 (2015).

11. Ankel, W. E. Erwerb und Aufnahme der Nahrung bei den Gastropoden. Verhandlungen der Deutschen Zoologischen Gesellschaft. 11, 223-295 (1938).

12. Eigenbrodt, H. Untersuchungen über die Funktion der Radula einiger Schnecken. Zeitschrift für Morphologie und Ökologie der Tiere. 37 (4), $735-791$ (1941).

13. Crampton, D. M. Functional anatomy of the buccal apparatus of Onchidoris bilamellata (Mollusca: Opisthobranchia). Transactions of the Zoological Society of London. 34, 45-86 (1977).

14. Wägele, H. Rasterelektronenmikroskopische Untersuchungen an Radulae einiger Nordseeschnecken (Gastropoda: Prosobranchia) mit Anmerkungen zur Funktionsmorphologie. Drosera. 83 (1), 68-78 (1983).

15. Hawkins, S. J. et al. A comparison of feeding mechanism in microphagous, herbivorous, intertidal, prosobranchs in relation to resource partitioning. Journal of Molluscan Studies. 55, 151-165 (1989).

16. Scheel, C., Gorb, S. N., Glaubrecht, M. \& Krings, W. Not just scratching the surface: distinct radular motion patterns in Mollusca. Biology Open. 9, bio055699 (2020). 
17. Ankel, W. E. Die Fraßspuren von Helcion und Littorina und die Funktion der Radula. Verhandlungen der Deutschen Zoologischen Gesellschaft. 38, 174$182(1936)$.

18. Märkel, K. Bau und Funktion der Pulmonaten-Radula. Zeitschrift für Wissenschaftliche Zoologie. 160, 213-289 (1957).

19. Märkel, K. Modell-Untersuchungen zur Klärung der Arbeitsweise der Gastropodenradula. Verhandlungen der Deutschen Zoologischen Gesellschaft. 18, 232-243 (1964).

20. Märkel, K. Über funktionelle Radulatypen bei Gastropoden unter besonderer Berücksichtigung der Rhipidoglossa. Vie et Milieu. 17, 1121-1138 (1966).

21. Richter, G. Die Schnecken'zunge' als Werkzeug. Natur und Museum. 92, 391-406 (1962).

22. Hickman, C. S. \& Morris, T. E. Gastropod feeding tracks as a source of data in analysis of the functional morphology of radulae. The Veliger. 27, $357-365$ (1985).

23. Janssen, H. H. \& Triebskorn, R. (1987). Comparative morphology of the radulae in Pomatia elegans and in Littorina littorea (Gastropoda: Taenioglossa). Zoologischer Anzeiger, 219, 73-82.

24. Shaw, J. A., Macey, D. J., Brooker, L. R. \& Clode, P. L. Tooth use and wear in three iron-biomineralizing mollusc species. Biol. Bull. 218, 132-144 (2010).

25. Frazzetta, T. H. The mechanics of cutting and the form of shark teeth (Chondrichthyes, Elasmobranchii). Zoomorphology. 108, 93-107 (1988).

26. Popowics, T. E. \& Fortelius, M. On the cutting edge: Tooth blade sharpness in herbivorous and faunivorous mammals. Ann. Zool. Fenn. 34, 73-88 (1997).

27. Freeman, P. W. et al. (1997). Puncturing ability of bat canine teeth: The tip. In: T. L. Yates (Eds.), Life Among the Muses: Papers in Honor of J.S. Findley (pp. 151-157). New Mexico, USA:Museum of Southwestern Biology.

28. Evans, A. R. \& Sanson, G. D. The effect of tooth shape on the breakdown of insects. Journal of Zoology. 246, 391-400 (1998).

29. Evans, A. R., Hunter, J., Fortelius, M. \& Sanson, G. D. The scaling of tooth sharpness in mammals. Ann. Zool. Fenn. 42, 603-613 (2005).

30. Shergold, O. A. \& Fleck, N. A. Experimental investigation into the deep penetration of soft solids by sharp and blunt punches, with application to the piercing of skin. Journal of Biomechanical Engineering. 127 (5), 838-848 (2005).

31. Freeman, P. W. \& Lemen, C. A. The trade-off between tooth strength and tooth penetration: predicting optimal shape of canine teeth. Journal of Zoology. 273, 273-280 (2007)

32. Whitenack, L. B. \& Motta, P. J. Performance of shark teeth during puncture and draw: implications for the mechanics of cutting. Biological Journal of the Linnaean Society. 100, 271-286 (2010).

33. Jones, D., Evans, A. R., Siu, K. K. W., Rayfield, E. J. \& Donoghue, P. C. J. (2012). The sharpest tools in the box? Quantitative analysis of conodont element functional morphology. Proceedings of the Royal Society B: Biological Sciences, 279, 2849-2854.

34. Anderson, P. S. L. Making a point: shared mechanics underlying the diversity of biological puncture. Journal of Experimental Biology. 221 (22), jeb187294 (2018).

35. Gmelin, J. F. (1791). Vermes. In: J. F. Gmelin (Ed.), Caroli a Linnaei Systema Naturae per Regna Tria Naturae (Ed. 13., Tome 1(6), pp. 3021-3910). Leipzig, Germany: G. E. Beer, Lipsiae.

36. Eichhorst, T. E. Neritidae of the World: Volume 1 and 2 (ConchBooks, Hackenheim, Germany, 2016).

37. Holznagel, W. E. A nondestructive method for cleaning gastropod radulae from frozen, alcohol-fixed, or dried material. American Malacological Bulletin. 14, 181-183 (1998).

38. Grunenfelder, L. K. et al. Stress and damage mitigation from oriented nanostructures within the radular teeth of Cryptochiton stelleri. Adv. Funct. Mater. 24, 6093-6104 (2014).

39. Krings, W., Marcé-Nogué, J., Karabacak, H., Glaubrecht, M. \& Gorb, S. N. Finite element analysis of individual taenioglossan radula teeth (Mollusca). Acta Biomater. 115 (1), 317-332 (2020).

40. Baker, H. B. (1923). Notes on the radula of the Neritidae. Proceeding of the Academy of Natural Sciences of Philadelphia, 75, 117-178.

41. Eales, N. B. Aplysia. Liverpool Marine Biology Committee: Memoirs. 24, 1-91 (1921).

42. Howells, H. H. The structure and function of the alimentary canal of Aplysia punctata. Quarterly Journal of Microscopical Science. 83, 357-397 (1942).

43. Solem, A. Patterns of radular tooth structure in carnivorous land snails. The Veliger. 17, 81-88 (1974).

44. Hickman, C. S. Gastropod radulae and the assessment of form in evolutionary paleontology. Paleobiology. 6 (3), $276-294$ (1980).

45. Smith, D. A. Radular kinetics during grazing in Helisoma trivolvis (Gastropoda: Pulmonata). Journal of Experimental Biology. 136, 89-102 (1988).

46. Morris, T. E. \& Hickman, C. S. A method for artificially protruding gastropod radulae and a new model for radula function. The Veliger. 24 (2), $85-89$ (1981).

47. Hickman, C. S. Evolution and function of asymmetry in the archaeogastropod radula. The Veliger. 23 (3), 189-194 (1981).

48. Katsuno, S. \& Sasaki, T. Comparative histology of radula-supporting structures in Gastropoda. Malacologia. 50 (1-2), 13-56 (2008).

49. Barroso, C. X., Matthews-Cascon, H. \& Simone, L. R. L. Anatomy of Neritina zebra from Guyana and Brazil (Mollusca: Gastropoda: Neritidae). Journal of Conchology. 41 (1), 49-64 (2012).

50. Simone, L. R. L. (2018). Phenotypic features of Helicina variabilis (Gastropoda: Neritimorpha) from Minas Gerais, Brazil. Papéis Avulsos de Zoologia, 58, e20185832.

51. Krings, W., Brütt, J. O., Gorb, S. \& Glaubrecht, M. Tightening it up: Diversity of the chitin anchorage of radular-teeth in paludomid freshwater-gastropods. Malacologia. 63 (1), 77-94 (2020b). 
52. Krings, W., Kovalev, A., Glaubrecht, M. \& Gorb, S. N. Differences in the Young modulus and hardness reflect different functions of teeth within the taenioglossan radula of gastropods. Zoology. 137, 125713 (2019).

53. Mischor, B. \& Märkel, K. (1984). Histology and regeneration of the radula of Pomacea bridgesi (Gastropoda, Prosobranchia). Zoomorphology, 104, $42-66$.

54. Neustadter, D., Drushel, M., Crago, R. F., Adams, P. E. \& Chiel, H. J. A kinematic model of swallowing in Aplysia californica based on radula/odontophore kinematics and in vivo magnetic resonance images. Journal of Experimental Biology. 205, 3177-3206 (2002).

55. Vortsepneva, E. \& Tzetlin, A. General morphology and ultrastructure of the radula of Testudinalia testudinalis (O. F. Müller, 1776) (Patellogastropoda, Gastropoda). Journal of Morphology. 280 (11), 1714-1733 (2019).

56. Montroni, D. et al. Structural characterization of the buccal mass of Ariolimax californicus (Gastropoda; Stylommatophora). PLoS One. 14 (8), (2019). e0212249

57. LeBlanc, A. R. H., Brink, K. S., Whitney, M. R., Abdala, F. \& Reisz, R. R. (2018). Dental ontogeny in extinct synapsids reveals a complex evolutionary history of the mammalian tooth attachment system. Proceedings of the Royal Society B: Biological Sciences, 285, 20181792.

58. Bemmann, M. et al. (2020). Movement analysis of primate molar teeth under load using synchrotron X-ray microtomography.Journal of Structural Biology, 107658 .

59. Runham, N. W. \& Thornton, P. R. Mechanical wear of the gastropod radula: a scanning electron microscope study. Journal of Zoology. 153, 445-452 (1967).

60. Carriker, M. R., Schaadt, J. G. \& Peters, V. (1974). Analysis by slow-motion picture photography and scanning electron microscopy of radular function in Urosalpinx cinerea follyensis (Muricidae, Gastropoda) during shell penetration. Marine Biology, 25, 63-76.

61. Wiesel, R. \& Peters, W. Licht- und elektronenmikroskopische Untersuchungen am Radulakomplex und zur Radulabildung von Biomphalaria glabrata Say (= Australorbis gl.). Basommatophora). Zoomorphologie. 89, 73-92 (1978). Gastropoda

62. Franz, C. J. Feeding patterns of Fissurella species on Isla de Margarita, Venezuela: use of radulae and food passage rates. Journal of Molluscan Studies. 56, 25-35 (1990).

63. van der Wal, P., Giesen, H. J. \& Videler, J. J. Radular teeth as models for the improvement of industrial cutting devices. Materials Science and Engineering: C. 7, 129-142 (1999).

64. Shaw, J. A., Brooker, L. R. \& Macey, D. J. Radula tooth turnover in the chiton, Acanthopleura hirtosa (Blainville, 1825) (Mollusca: Polyplacophora). Molluscan Research. 22, 93-99 (2002).

65. Anistratenko, V. V., Ryabceva, Y. S. \& Degtyarenko, E. V. Morphological traits of the radula in Viviparidae (Mollusca, Caenogastropoda) as a master key to discrimination of closely related species. Vestnik Zoologii. 47 (2), 40-51 (2013).

66. Jenkins, S. R. \& Hartnoll, R. G. Food supply, grazing activity and growth rate in the limpet Patella vulgata L.: A comparison between exposed and sheltered shores. Journal of Experimental Marine Biology and Ecology. 258 (1), 123-139 (2001).

67. Weaver, J. C. et al. Analysis of an ultra hard magnetic biomineral in chiton radular teeth. Mater. Today. 13, 42-52 (2010).

68. Lu, D. \& Barber, A. H. Optimized nanoscale composite behaviour in limpet teeth. Journal of the Royal Society Interface. 9, 1318-1324 (2012).

69. Barber, A. H., Lu, D. \& Pugno, N. M. Extreme strength observed in limpet teeth. Journal of the Royal Society Interface. 12 (105), 20141326 (2015).

70. Macey, D. J., Brooker, L. R. \& Cameron, V. Mineralisation in the teeth of the gastropod mollusc Nerita atramentosa. Molluscan Research. 18, 33-41 (1997).

71. Padilla, D. K. Form and function of radular teeth of herbivorous molluscs: Focus on the future. American Malacological Bulletin. 18 (1/2), $163-168$

(2003).

72. Fretter, V. Functional studies of the anatomy of some neritid prosobranchs. Journal of Zoology. 147 (1), 46-74 (1965).

73. Steneck, R. S. \& Watling, L. Feeding Capabilities and limitation of herbivorous molluscs: A functional group approach. Mar. Biol. 68, 299-319 (1982).

74. Hickman, C. S. Implication of radula tooth-row functional integration for archaeogastropod systematics. Malacologia. 25 (1), 143-160 (1984).

75. van der Wal, P. Structural and material design of mature mineralized radula teeth of Patella vulgata (gastropoda). Journal of Ultrastructure Research. 102 (2), 147-161 (1989).

76. Killian, C. E. et al. Self-sharpening teeth: self-sharpening mechanism of the sea urchin tooth. Adv. Funct. Mater. 21, $682-690$ (2011).

\section{Figures}




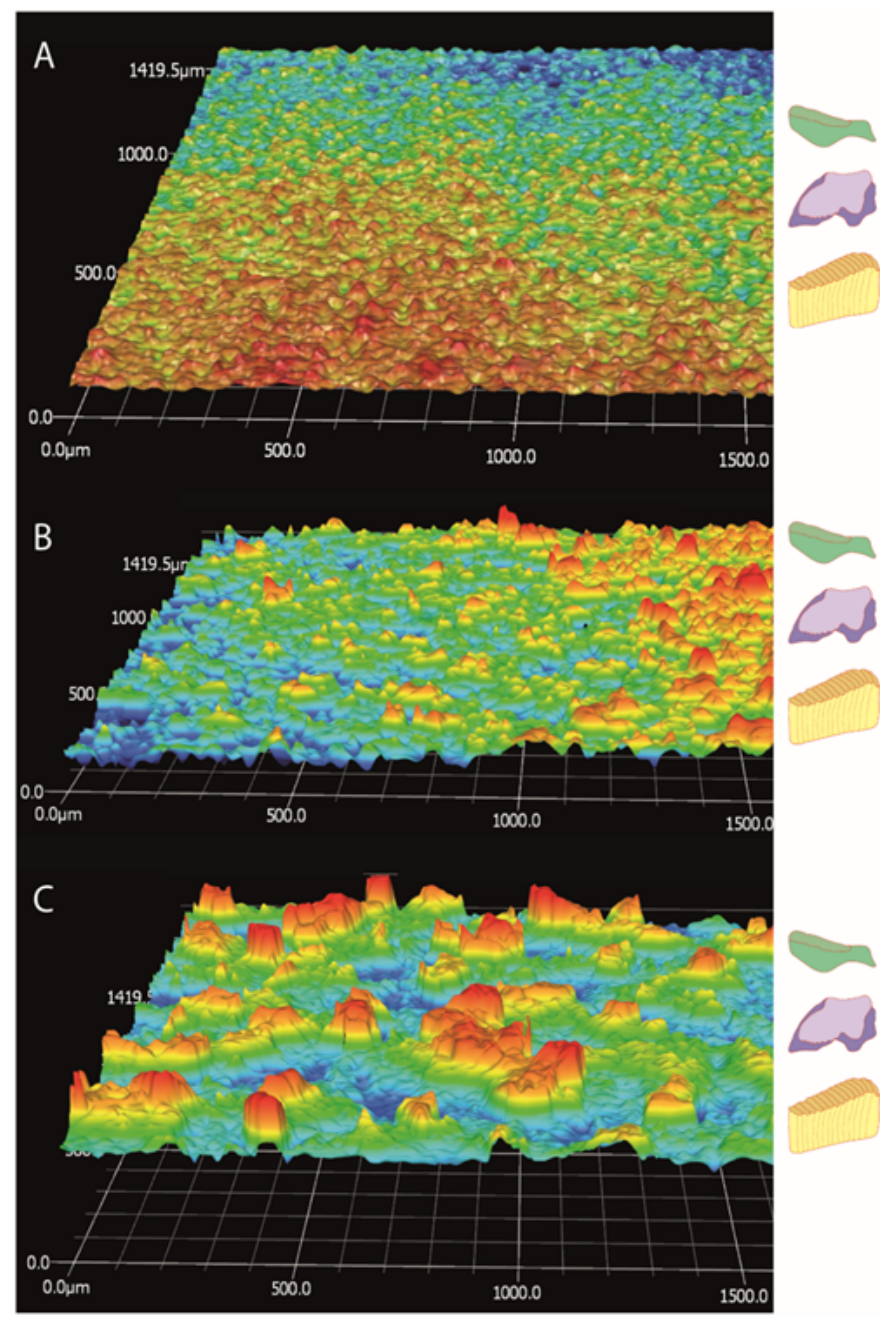

\section{Figure 1}

Relative dimensions of sandpaper profiles used in the experiments and radular teeth of the species studied. Left side: Surface profile of sandpapers visualized with the Keyence VR 3100. A = super fine (P 800), B = extra fine (P 600), C = very fine ( $P$ 180) sandpaper; scale bars are in $\mu \mathrm{m}$. Right side: schematic illustration of the distinct tooth types exhibiting signs of wear (lateral I, lateral II, inner marginals) scaled identically to the sandpapers. 


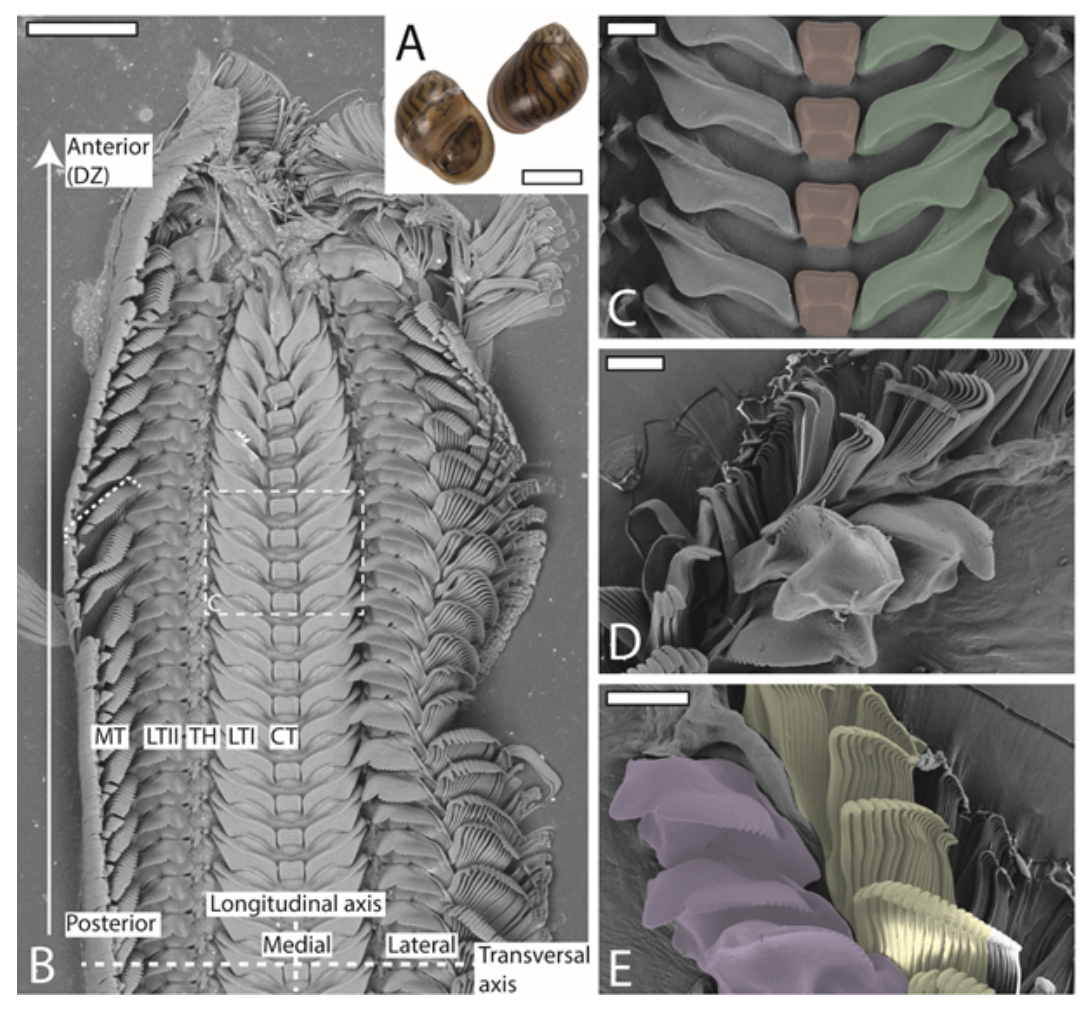

\section{Figure 2}

A. Shell of Vittina turrita. B-E. SEM images of one radula from the control group. B. Image of the outermost part of the radula (wear and digestive zone; the arrow points in the direction of tooth loss) with the definition of the anatomical directions (medial, lateral, anterior, posterior) and the radular axes (transversal and longitudinal axis). C. Central teeth (red) and lateral teeth (green). D-E. Lateral tooth II (purple) and inner 15 marginal teeth (yellow) of degenerative zone. $\mathrm{CT}=$ central tooth, $\mathrm{DZ}$ = degenerative zone, $\mathrm{LTI}=$ lateral tooth I, $\mathrm{LTII}=$ lateral tooth II, MT = marginal teeth, $\mathrm{TH}=$ thickening of membrane/interlocking teeth . Scale bars: $A=30 \mathrm{~mm}, \mathrm{~B}=250 \mu \mathrm{m}, \mathrm{C}-\mathrm{E}: 60 \mu \mathrm{m}$. 
A

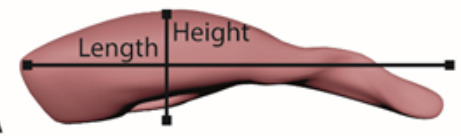

B
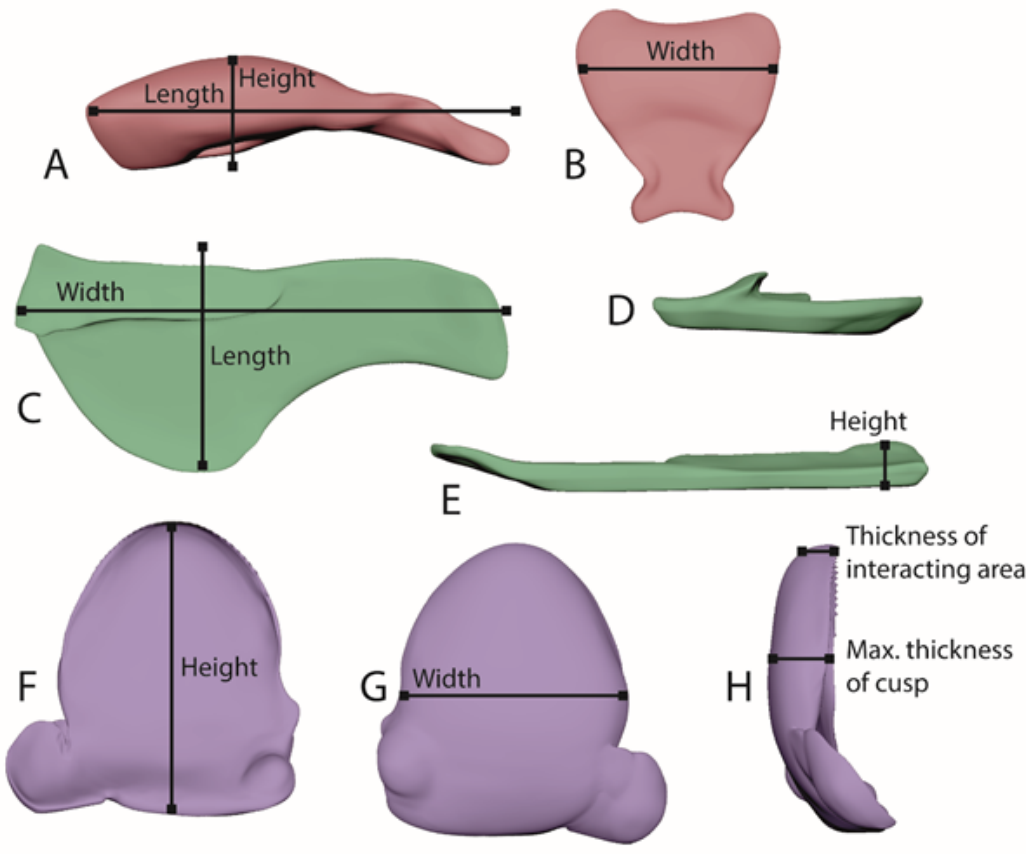

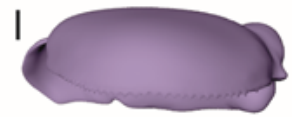

Thickness
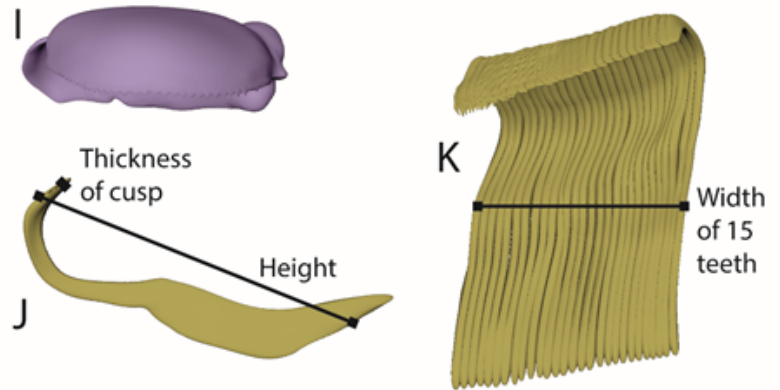

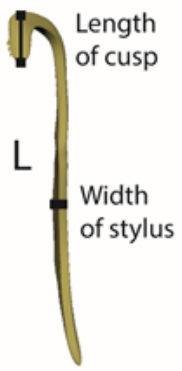

Figure 3

3D models of the distinct tooth types for defining of the parameters measured (height, width, length, thickness). A-B. Central tooth. A. Lateral view. B. Ventral view. C-E. Lateral tooth I. C. Ventral view. D. Medial view. E. View from anterior. F-I. Lateral tooth II. F. View from posterior. G. View from anterior. H. Lateral view. I. Ventral view. J-L. Inner marginal teeth. J. Lateral view. K-L. Ventral view. 


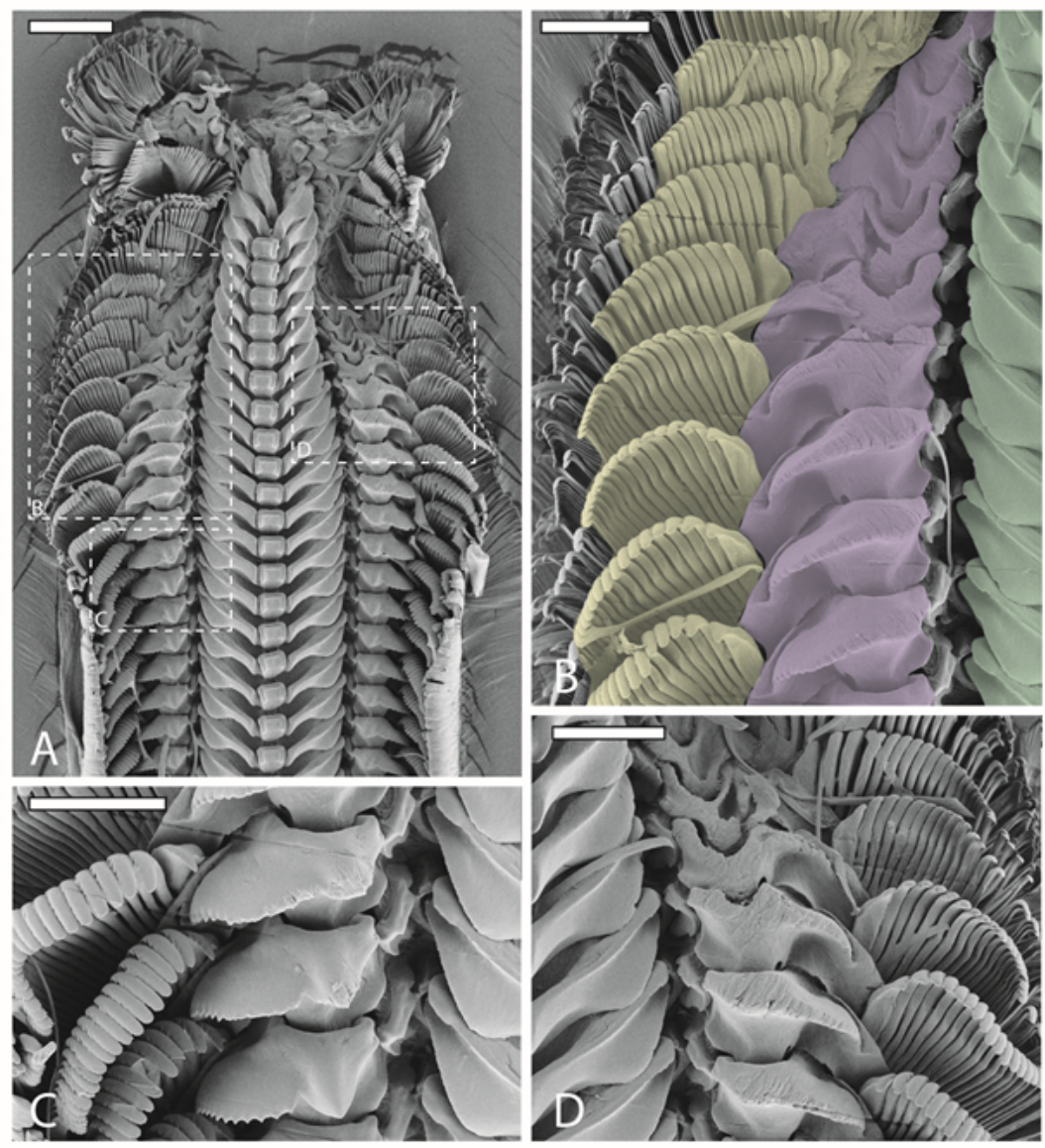

Figure 4

SEM images of one radula from the specimen sheltered on the super fine sandpaper. A. Image of the outermost part of the radula (wear and digestive zone). B-D. Magnifications of the same region as in A. B. Right wear zone with colored outlines of lateral teeth I (green), lateral teeth II (purple), and inner 15 marginal teeth (yellow; only marginal teeth that show signs of wear were colored). C. The first signs of wear on lateral tooth I, lateral tooth II, marginal teeth. D. Left wear zone. Scale bars: $A=200 \mu \mathrm{m}, \mathrm{B}-\mathrm{D}=100 \mu \mathrm{m}$. 


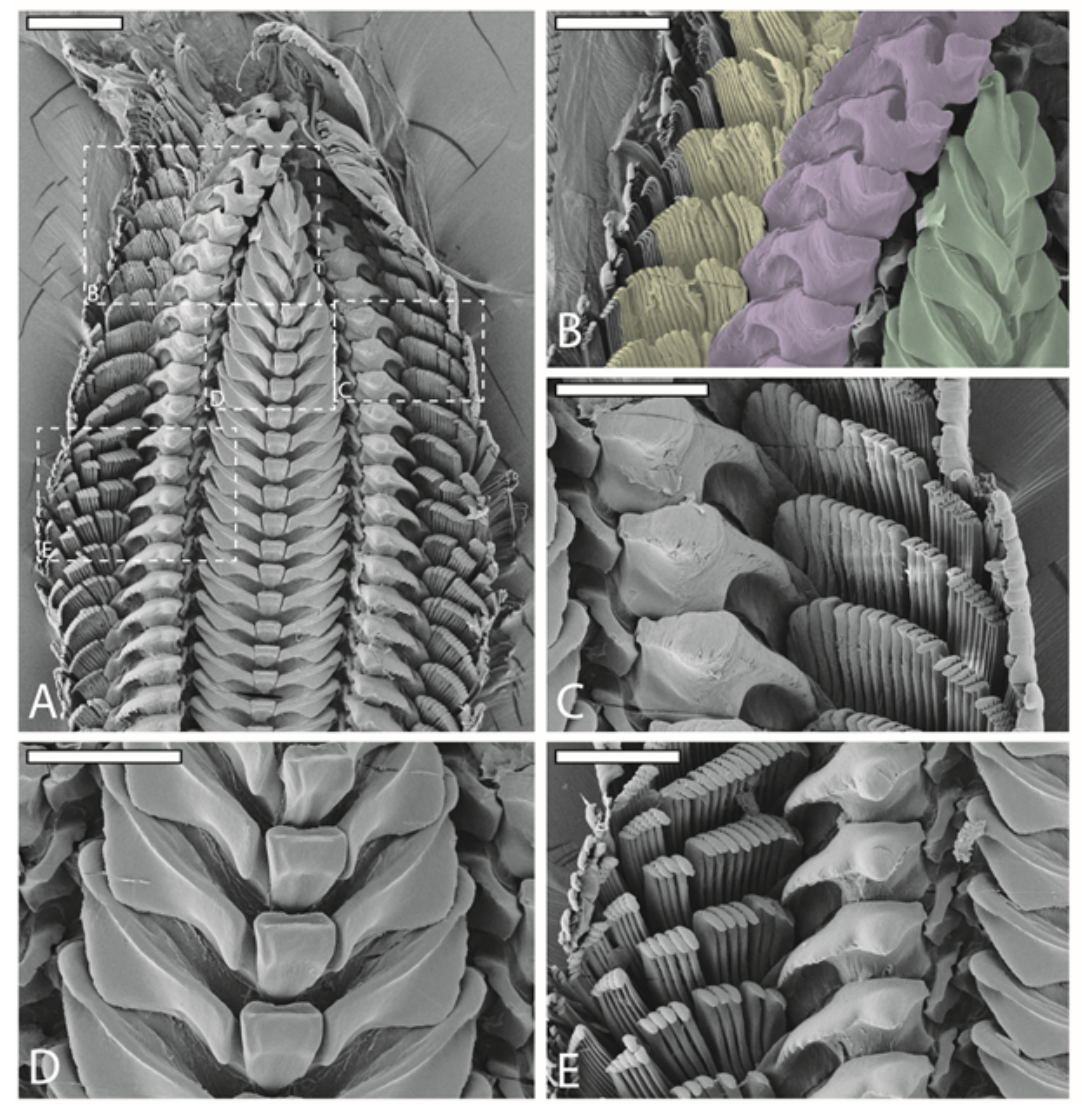

\section{Figure 5}

SEM images of one radula from the specimen sheltered on the extra fine sandpaper. A. Image of the outermost part of the radula (wear and digestive zone). B-E. Magnifications of the same region as in A. B. Right wear zone with colored outlines of lateral teeth I (green), lateral teeth II (purple), and inner 15 marginal teeth (yellow; only marginal teeth that show signs of wear were colored). C. Left wear zone. D. Worn lateral teeth I and unworn central teeth. E. The first signs of wear on lateral teeth I, lateral teeth II, and marginal teeth. Scale bars: $A=200 \mu \mathrm{m}, \mathrm{B}-\mathrm{E}=100 \mu \mathrm{m}$. 


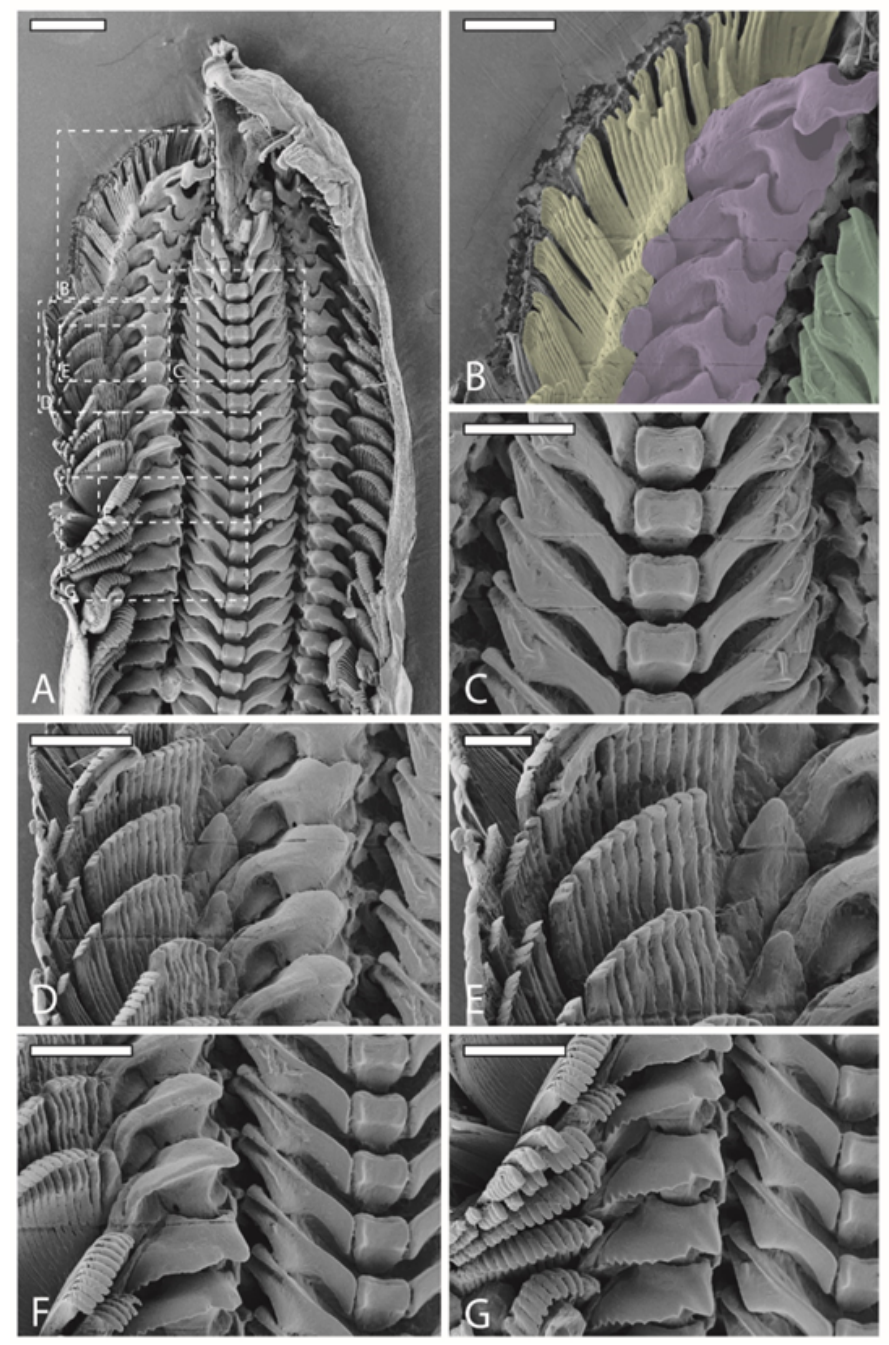

Figure 6

SEM images of one radula from specimen sheltered on the very fine sandpaper. A. Image of the outermost part of the radula (wear and digestive zone). B-G. Magnifications of the same region as in A. B. Right wear zone with colored outlines of lateral teeth I (green), lateral teeth II (purple), and 15 inner marginal teeth (yellow; only marginal teeth that show signs of wear were colored). C. Worn lateral teeth I and unworn central teeth. D-E. Worn lateral teeth I, lateral teeth II, marginal teeth. F. Slight signs of wear. G. The first signs of wear on lateral tooth I, lateral tooth II, and marginal teeth. Scale bars: $A=200 \mu m, B-G=100 \mu m$.
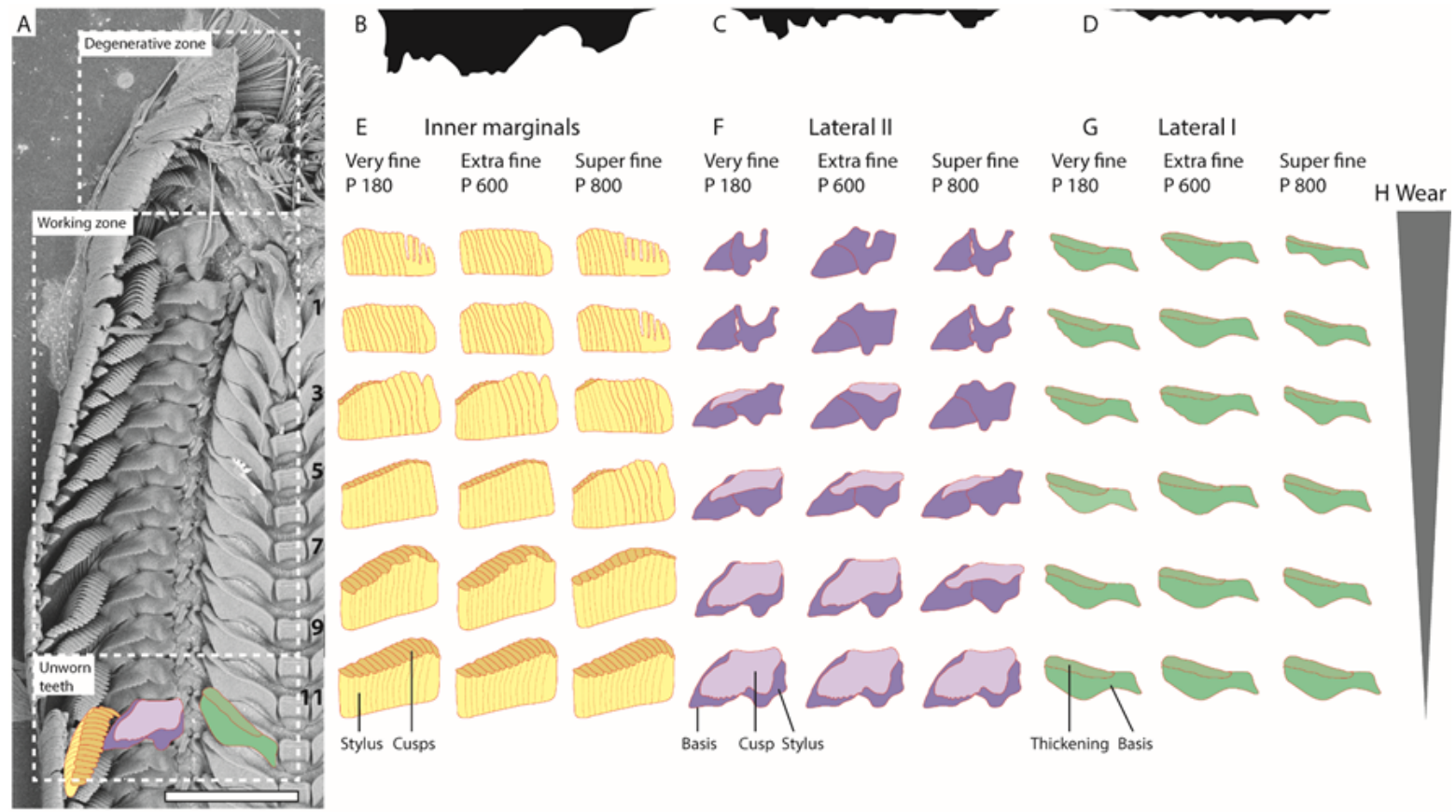

$c$ The

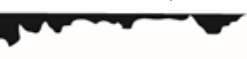

D 
Figure 7

A. SEM images of one radula from specimen of control group, with distinct zones (degenerative zone, working zone, unworn teeth) depicted; schematic illustrations of teeth were plotted on the SEM image to allow identification of tooth schemes $(E-G)$, scale bar $=200 \mu m$. B-D. Schemes of the sandpapers used (B. very fine, C. extra fine, D. super fine) scaled identically to tooth scheme dimensions $(E-G)$. E-G. Schematic illustration of tooth types (inner 15 marginals: stylus = yellow, cusps = orange; lateral I: basis and stylus = purple, cusp = light purple; lateral II: basis = green, thickening = dark green) of every other row (tooth rows 1-11), to depict the area loss due to the sandpaper-tooth contact (wear patterns) for each sandpaper type (very fine, extra fine, super fine). H. Degree of wear from posterior (not worn) to anterior (highly worn).
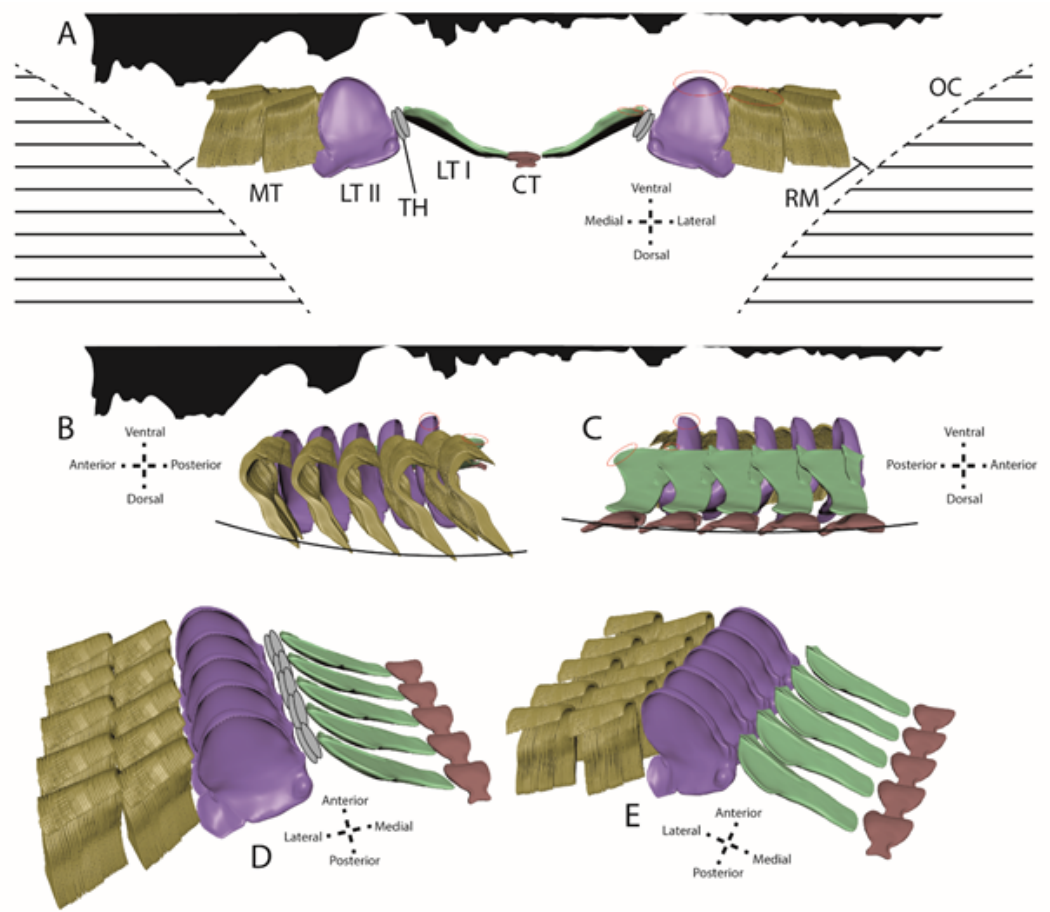

Figure 8

Visualization of the proposed position of teeth on the radular membrane between the two odontophoral cartilages during foraging in different views (see axes for anatomical orientation). Silhouettes of the sandpapers used (from left to right: very fine, extra fine, super fine) in A-C are scaled identically to the dimensions of teeth. Contact areas are highlighted in red. A. Frontal view depicting the inverse w-shape of the membrane. B-C. Lateral and medial views depicting additionally a curvature of the membrane towards dorsal. D-E. Curvature from latero-ventral and medio-ventral view. $\mathrm{CT}=\mathrm{central}$ tooth, $\mathrm{LTI}=\mathrm{Iateral}$ tooth I, LTII = lateral tooth II, MT = marginal teeth, $\mathrm{OC}=$ odontophoral cartilage, $\mathrm{RM}=$ radular membrane, $\mathrm{TH}=$ thickening of membrane/ interlocking teeth . 


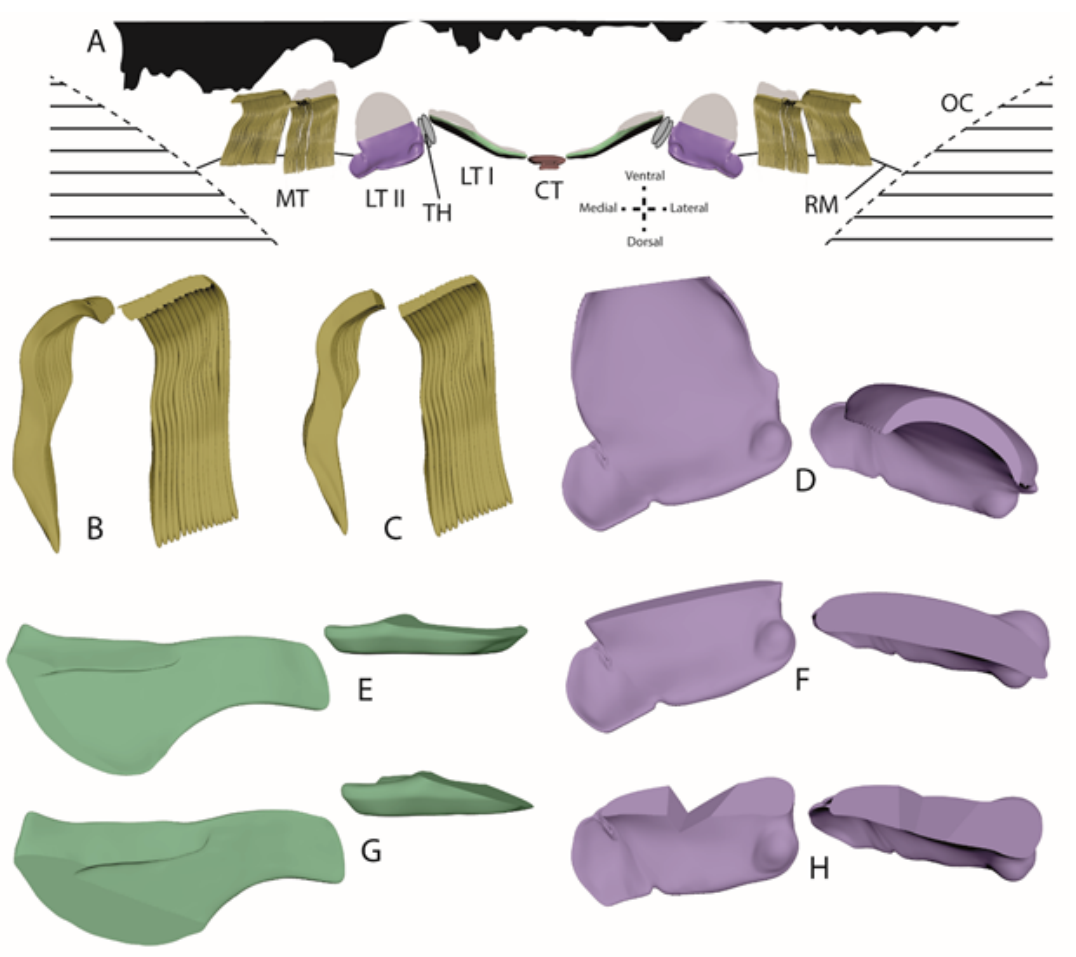

Figure 9

A. Visualization of the proposed position of maximally worn teeth on the radular membrane between the two odontophoral cartilages from frontal view (see axis for anatomical orientation). Silhouettes of the sandpapers used (from left to right: very fine, extra fine, super fine) are scaled identically to the dimensions of teeth. In grey are the silhouettes of the unworn teeth. B-H. 3D models with modeled worn condition of teeth (B-C. inner 15 marginal teeth, D, F, H. lateral tooth II, E, G. lateral tooth I). B. Wear on the 5 th tooth row induced by the very fine sandpaper. C. Wear on the 1 st tooth row induced by the super fine sandpaper. D. Wear on the 7th tooth row induced by the extra fine sandpaper. E. Wear on the 1st tooth row induced by the extra fine sandpaper. F. Wear on the 3rd tooth row induced by the extra fine sandpaper. G. Wear on the 1 st tooth row induced by the super fine sandpaper. H. Wear on the $1 \mathrm{st}$ tooth row induced by the super fine sandpaper. See Tab. 3 for volume loss in \%.
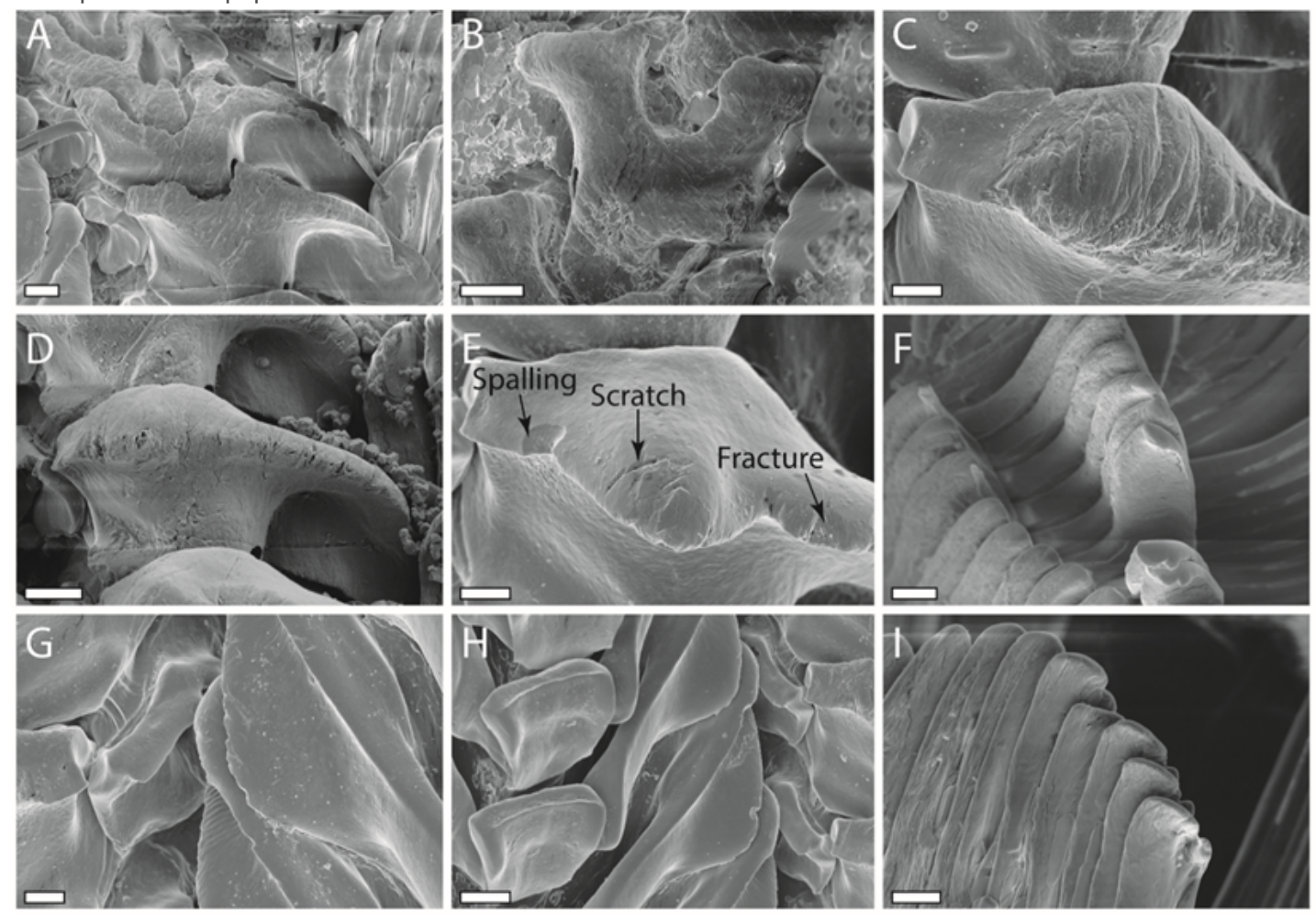

Figure 10 
Detailed SEM images of worn radular teeth depicting different kinds of wear (spalling, scratch, fracture). A-E. Lateral tooth II. F, I. Inner marginal teeth. G-H. Lateral tooth I. Scale bars: A, D, E, H = $20 \mu \mathrm{m}, \mathrm{B}, \mathrm{C}, \mathrm{F}, \mathrm{G}=10 \mu \mathrm{m}, \mathrm{I}=5 \mu \mathrm{m}$.

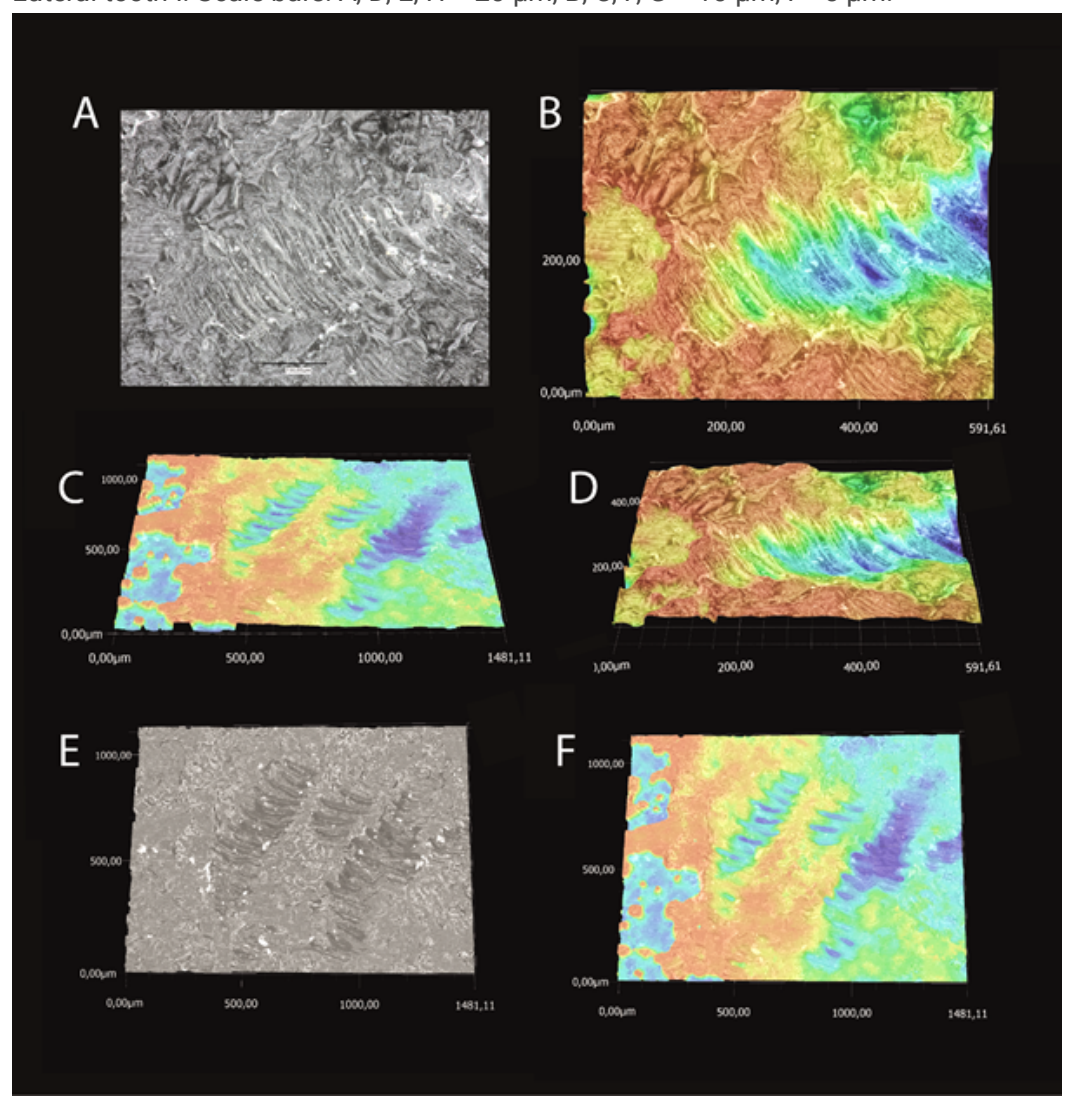

\section{Figure 11}

Feeding tracks left by the mollusks on the paraffin surface. Only the traces of the lateral tooth II cusps are clearly visible. A-B, C. Feeding track I from different perspectives: A. Stacked image in SEM optic; B, D. Colored surface texture visualized with the Keyence VHX-7000. C, E-F. Feeding track II from different perspectives: E. Stacked image in SEM optic; C, F. Colored surface texture visualized with the Keyence VHX-7000. Dimensions are given in $\mu m$. 